\title{
Younger Adults Are More Likely to Increase Fruit and Vegetable Consumption and Decrease Sugar Intake with the Application of Dietary Monitoring
}

\author{
Louisa Ming Yan Chung ${ }^{1, * \mathbb{D}}$, Shirley Siu Ming Fong ${ }^{1}$ and Queenie Pui Sze Law ${ }^{2}$ \\ 1 Department of Health and Physical Education, The Education Unversity of Hong Kong, Tai Po, \\ New Territories, Hong Kong, China; smfong@eduhk.hk \\ 2 School of Nursing, Tung Wah College, Homantin, Kowloon, Hong Kong, China; queenielaw@twc.edu.hk \\ * Correspondence: chungmy@eduhk.hk
}

Citation: Chung, L.M.Y.; Fong, S.S.M.; Law, Q.P.S. Younger Adults Are More Likely to Increase Fruit and Vegetable Consumption and Decrease Sugar Intake with the Application of Dietary Monitoring. Nutrients 2021, 13, 333. https://doi.org/10.3390/ nu13020333

Received: 2 December 2020

Accepted: 20 January 2021

Published: 23 January 202

Publisher's Note: MDPI stays neutral with regard to jurisdictional claims in published maps and institutional affiliations.

Copyright: (c) 2021 by the authors. Licensee MDPI, Basel, Switzerland. This article is an open access article distributed under the terms and conditions of the Creative Commons Attribution (CC BY) license (https:// creativecommons.org/licenses/by/ $4.0 /)$.

\begin{abstract}
Establishing healthy eating habits is considered to be a sustainable strategy for health maintenance, and mobile applications (apps) are expected to be highly effective among the youngaged population for healthy eating promotion. The purpose of this study was to investigate the effectiveness of a dietary monitoring app on younger adults' nutrition knowledge and their dietary habits. A controlled-experimental study was performed with one experimental group having a three-hour nutrition seminar and 12 weeks of dietary monitoring with the app, and one control group receiving a three-hour nutrition seminar. Behavioral feedback delivered by the app was evaluated in facilitating the transfer of nutritional knowledge to nutrition behavior. A total of 305 younger adults aged from 19 to 31 were recruited. Baseline and post-intervention nutrition knowledge and dietary behavior were collected. All mean scores of post-GNKQ-R increased from baseline for both the control and the experimental groups. The mean differences of sugar intake, dietary fiber intake, and vitamin $\mathrm{C}$ intake for the experimental group were significantly more than those for the control group (all $p<0.001$ ). In addition, the experimental group increased fruit and vegetable consumption significantly more than the control group (all $p<0.001$ ). For those younger adults with a relatively large body size, they were more likely to increase fruit consumption with the application of dietary monitoring.
\end{abstract}

Keywords: younger adults; dietary monitoring apps; behavioral feedback; fruit and vegetable consumption; nutrition knowledge

\section{Introduction}

In recent decades, young adults aged 18-24 are found to be gaining weight more rapidly than their prior generations [1]. Indeed, weight gain is prominent among those aged 18-35 in most developed countries. For instance, 35\% of U.S. young adults and $27.9 \%$ of the Australian young population are shown to be obese [2-4]. Moreover, the Population Health Survey [5] revealed that 50\% of Hong Kong adults aged 15-84 were either overweight or obese. Particularly in populations under 30-years-old, insufficient intake of wholegrains, fruits, and vegetables, but abundant intake of discretionary foods, such as sugar-sweetened beverages, are ubiquitous [6,7]. In addition, in the transition from attending high school to beginning their employment, young adults also have greater food intake outside of the home [8], inevitably leading to higher energy intake from convenience foods, alcoholic beverages, take-out food, and other high-density, low-nutrient foods [9]. This trend is particularly alarming because a higher body mass index in early adulthood increases the risk of progressive metabolic syndrome by 21 times for men and 27 times for women in the subsequent 15 years [10]. Therefore, establishing healthy eating habits is considered a sustainable and highly effective strategy for health maintenance and the prevention of chronic illnesses [11,12]. 
In Hong Kong, the government established a committee to create a strategic plan to reduce dietary salt and sugar intake in the Hong Kong population [13]. The work of the committee included public education to promote awareness of healthy eating and transferring knowledge about balanced diets [14]. Indeed, acquisition of nutrition knowledge plays a pivotal role in positively changing people's eating behavior [15]. Younger adults, however, are found to lack skills in planning, purchasing, preparing, and cooking healthy meals at home, and tend to select nutritionally-inadequate pre-packaged foods [16]. Younger adults also seem to constitute a group that is lacking family support in consuming healthy meals, while simultaneously also not ready to assume responsibility for eating healthfully $[17,18]$. Self-efficacy constitutes the essential determinant to promote nutrition behavior and education is found effective to increase one's self-efficacy [19]. Younger working groups have been shown to require innovative nutrition education to make healthy food choices [19]. Recently, nutrition education has radically transformed from descriptive to interactive modalities, i.e., from face-to-face to instant messaging, social media, the Internet, and mobile applications (apps) [20-23]. Indeed, rapid advancements in technology have markedly shifted health communication in a timely, interactive, and interdisciplinary direction. This integration of knowledge transfer about healthy eating with mobile apps is essential for those technology-immersed younger population [24]. Healthy eating promotion, if conducted with appropriate technology applications, facilitates users to acquire information flexibly in time, pace, and place. Another major advantage of technology application is its specific fit to individual needs, and it allows reflection [22]. To promote healthy eating efficaciously, nutrition knowledge necessitates both education and reflection [25]. Through reflective practices, positive changes in eating habits can be expected [25].

Although mobile apps are anticipated to be suitable for the young-aged population for healthy eating promotion, commercial apps are largely absent in theoretical support and lack sustained engagement with users [26]. Indeed, limited studies exist that target younger adults to change their nutrition knowledge or promote healthy eating with applications of technology-assisted nutrition education. There are also few interventions that apply mobile application (apps) to improve younger adults' nutrition behavior. In this study, a dietary monitoring mobile app, called the "eDietary Portal", integrated with a behavioral feedback component, was evaluated in younger adults aged 19-39. The primary aims were to investigate the effectiveness of a dietary monitoring app on younger adults' nutrition knowledge and dietary habits.

\section{Research Questions}

1. Does the dietary monitoring app enhance nutritional knowledge among younger adults?

2. Does the dietary monitoring app increase the consumption of fruits and vegetables among younger adults?

3. Does the dietary monitoring app decrease the consumption of salt and sugar among younger adults?

4. Does the dietary monitoring app increase the consumption of whole grains among younger adults?

\section{Methods}

\subsection{Design and Setting}

This was a quasi-experimental two-group design, with one experimental group having nutrition education and the dietary monitoring app as an intervention, and one control group receiving usual nutrition education. The study design aimed to determine whether the behavioral feedback delivered by the app was effective in facilitating the transfer of nutritional knowledge to nutrition behavior.

The sampling was convenience sampling at 12 selected locations with alternate assignment to the control group and experimental group, until the target number for each group $(n=150)$ was reached. Physical measurements and nutrition education were conducted 
in activity rooms in community centers and lecture rooms in institutions. Ten non-profit organizations (NGOs) and two tertiary institutions were invited to recruit participants and to provide venues for the research team to carry out nutrition education. The NGOs were those providing community services to populations living in the districts.

\subsection{Participants}

A total of 305 younger adults aged 19-31 were recruited as participants. Inclusion criteria were as follows: Hong Kong younger adults aged 18-39; able to read and write Chinese; possess a hand-held device with iOS or Android platform to access the dietary monitoring app; and no prior education on nutrition. Exclusion criteria were as follows: those with special diets due to religion; having one or more chronic disease; and following a prescribed meal plan for weight reduction.

\subsection{Intervention}

Three hours of nutrition education and 12 weeks of self-dietary monitoring practice constituted the two activities implemented for the experimental group. The methodologies of this project followed a series of published works [26,27]. The protocol, including a three-hour nutrition lesson with 12 weeks participants' continuous reflection of their own diets, was found to be effective to change obese adults and adolescents' dietary habits and nutrition knowledge $[28,29]$. The nutrition lessons were arranged in a classroom setting, covering nutritional knowledge regarding food choices, the benefits of common nutrients, diet and diseases, healthy diets, as well as the relationship between diet and exercise. The nutrition lessons transferred the participants' basic knowledge of healthy eating and methods to maintain a healthy lifestyle with exercise.

Physical measurements of the participants and their age, sex, and daily physical activity levels were input to the app for both the control group and the experimental group. Participants in the experimental group recorded their daily intake on the dietary monitoring app by taking photographs of their foods and inputting the intake servings. Dietary reports with nutrient analysis were shown online for the participants to review. The participants reflected on their dietary intake by reviewing the online reports to check if there was excessive intake of undesirable nutrients or deficient intake of desirable nutrients. They were asked to change their food choices day by day and eat towards their healthy goal. Their self-reflection and change in eating patterns were recorded by the app in a central database. The nutritional knowledge that the participants received in the nutrition education, and reflection in the daily recording and reviewing process, was intended to facilitate the participants to acquire healthy eating behavior. Nutrition behavior established in the process of reflective learning generated by the reflective feedback was expected [30]. Participants in the control group attended the three-hour nutrition education with content that was similar to that in the experimental group. The participants in the control group only recorded their diet in the first week and the twelfth week as baseline and post-intervention measurements, respectively. They did not monitor their dietary pattern between the pre-post measurements. No online report with behavioral feedback was involved.

\subsection{Outcome Measurements}

\subsubsection{Nutrition Knowledge}

Nutrition knowledge was measured by the General Nutritional Knowledge Ques tionnaire-Revised (GNKQ-R) [31]. This instrument has been demonstrated to be reliable and accurate to measure nutrition knowledge, and it is also sensitive to changes in nutrition knowledge. The 88-item version used in the current study was a revised version of the original version which comprised 111-items [32]. This revised version reduced the time of self-completion by the younger adults, while still maintaining a consistent, reliable, and sensitive test of nutrition knowledge change [33]. GNKQ-R had high internal reliability with Cronbach's alpha $=0.93$, and that of each section ranged from 0.70 to 0.86 . The intraclass correlation coefficients for the external reliability ranged from 0.72 to 0.89 [31]. 
The construct validity was tested with an effect size ranging from 0.5 to 1.2. [31]. The GNKQ$\mathrm{R}$ comprised four sections. Section 1 consisted of 21 items about younger adults' knowledge concerning expert advice on food choice. Section 2 consisted of 39 items about younger adults' knowledge about food group classification. Section 3 consisted of 13 items about choosing healthy foods. Finally, Section 4 consisted of 21 items about knowledge of health problems or diseases related to diet and weight management.

\subsubsection{Dietary Behavior}

Dietary behavior was measured in collective outcome variables: calorie intake and 11 nutrients intake. Energy requirements were calculated based on participants' age, sex, physical measurements, and daily physical activity level [34,35]. Calorie intake and nutrient intake reflected the quality of food choices, and these constituted indicators of a healthy diet. The 11 nutrients included carbohydrates, proteins, total fat, saturated fat, trans fatty acid, cholesterol, sugar, dietary fiber, sodium, calcium, and vitamin C. Nutrient analysis was conducted with Nutrition Pro Software and the Food Database of Center for Health Protection. Mean values of daily calorie intake and each of the 11 nutrients were calculated at baseline (week 1) and post-intervention (week 12).

\subsection{Procedure}

The study design and implementation were approved by the Human Ethics Research Committee of the Research Development Office at the serving institution of the first author. Cross-sector collaboration was conducted with non-profit organizations. The health educators were responsible to recruit younger adults in their serving communities. Interested participants received an information sheet describing the objectives and details of the nutrition education program, and signed consent forms before the program commenced. The participants self-administered the questionnaire on general nutritional knowledge as a baseline measurement. The nutrition lessons were taught by the health educators. The participants were introduced to the eDietary Portal for dietary self-monitoring, which was operated on mobile phones or tablet devices. The participants were taught how to use the eDietary Portal to record their food diet on a daily basis. Participants were requested to record their daily diet by capturing and uploading photographs of the foods that the participants ate. They could record their daily diet at home towards the end of each day. The nutrient analysis of the food items was carried out by the researchers.

To enhance healthy individuals to be in compliance with the program, strategies were added to the program to maintain participants' interest in modifying their eating habits. First, physical measurement and screening could be conducted by participants' appointment. Body weight, body fat, and blood pressure could be measured every month For those having abnormal physical measurements, regularly measurements motivated them to continue modifying their eating habits. Second, regular tips about eating topics were sent to all participants by instant messaging. All participants received information on how to eat healthfully on special occasions, different settings, as well as deconstruction of prominent myths about healthy eating. With the target age group and convenient mobile communication, the project team conducted mobile nutrition education, rather than seminar-basis education, to enhance the compliance of recruited participants.

User satisfaction interviews with three participants were carried out. These three interviewees were randomly invited. Because of the COVID-19 pandemic during the time of the user satisfaction interview, all of the interviews were conducted individually with the researcher by telephone. Interview scripts were recorded as audio files for verbatim transcription.

\subsection{Data Analysis}

ANCOVA analysis was carried out between groups on post-GNKQ-R scores as the dependent variables and the pre-GNKQ-R scores as controlled independent variables. ANCOVA analysis was also performed between groups on post-energy requirement, 
post-energy intake and post-nutrient intakes as dependent variables, and pre-energy requirement, pre-energy intake, and pre-nutrient intakes as controlled independent variables, respectively. Stepwise regression was carried out to elucidate how the independent variables (intervention groups, age, gender, nutrition knowledge, and BMI categories) contributed to significant variances on participants' post-fruit consumption and post-vegetable consumption. All significance levels were set at $\alpha=0.05$.

\section{Results}

In total, 305 younger adults were recruited to participate in this project. The mean (s.d.) age was 22.1 (2.11), and the age range was 19-31. After group allocation, 154 (50.5\%) participants were assigned to the control group, and 151 (49.5\%) participants were assigned to the experimental group. The mean (s.d.) age of younger adults in the control group was 22.3 (2.34), while that of younger adults in the experimental group was $21.9(1.84)(p>0.05)$. Demographic characteristics of the participants are presented in Table 1. Chi-square tests were used to determine if uneven demographic characteristics were distributed between the two groups. The ratio of male to female participants in both the control and the experimental groups was approximately $1: 2(p>0.05)$. The ratio of single to married was approximately $4: 1$ in both groups $(p>0.05)$. The majority of the participants were single and had no children, which could be expected because the target group of this project was younger adults aged 18-39, for whom becoming married and having children were comparatively uncommon. The education level for the experimental group was found significantly higher than that of the control group $(p<0.05)$.

Table 1. Demographic characteristics of the participants.

\begin{tabular}{|c|c|c|c|}
\hline & Control & Experiment & \\
\hline & $n(\%)$ & $n(\%)$ & \\
\hline $\begin{array}{c}\text { Sex } \\
\text { Male } \\
\text { Female } \\
\text { Marital status }\end{array}$ & $\begin{array}{c}51(33.1) \\
103(66.9)\end{array}$ & $\begin{array}{l}55(36.4) \\
96(63.6)\end{array}$ & $>0.05$ \\
\hline $\begin{array}{c}\text { Single } \\
\text { Married }\end{array}$ & $\begin{array}{c}128(83.1) \\
26(16.9 \%)\end{array}$ & $\begin{array}{c}122(80.8) \\
29(19.2)\end{array}$ & $>0.05$ \\
\hline $\begin{array}{c}\text { Number of children } \\
0 \\
1 \\
2 \\
\end{array}$ & $\begin{array}{c}138(89.6) \\
11(7.1) \\
5(3.2) \\
\end{array}$ & $\begin{array}{c}135(89.4) \\
4(2.6) \\
12(7.9)\end{array}$ & $<0.05$ \\
\hline $\begin{array}{l}\text { Highest level of education } \\
\text { Secondary school } \\
\text { Technical or trade certificate } \\
\text { Diploma } \\
\text { Bachelor degree }\end{array}$ & $\begin{array}{l}19(12.3) \\
50(32.5) \\
49(31.8) \\
36(23.4)\end{array}$ & $\begin{array}{l}11(7.3) \\
35(23.2) \\
51(33.8) \\
54(35.8)\end{array}$ & $<0.05$ \\
\hline $\begin{array}{c}\text { Living region } \\
\text { Hong Kong Island } \\
\text { Kowloon } \\
\text { New Territories }\end{array}$ & $\begin{array}{l}17(11.0) \\
41(26.6) \\
96(62.3)\end{array}$ & $\begin{array}{c}10(6.6) \\
33(21.9) \\
108(71.5)\end{array}$ & $>0.05$ \\
\hline
\end{tabular}

Since the proportion of recruited female participants was higher than the proportion of recruited male participants, the percentages of participants in different body size categories were found to be significant different. However, when the body size categories were tested separately within each sex, there were no significant differences between groups $(p>0.05)$ (Table 2). 
Table 2. Chi-square tests by group assignment.

\begin{tabular}{|c|c|c|c|c|c|c|}
\hline & & BMI $<19$ & $19<$ BMI $<23$ & $23<\mathrm{BMI}<25$ & BMI $>25$ & $p$-Value \\
\hline & & $n(\%)$ & $n(\%)$ & $n(\%)$ & $n(\%)$ & \\
\hline \multirow[t]{2}{*}{ Male } & Control group & $7(70.0)$ & $25(41.0)$ & $7(43.8)$ & $12(63.2)$ & $>0.05$ \\
\hline & Experimental group & $3(30.0)$ & $36(59.0)$ & $9(56.3)$ & $7(36.8)$ & \\
\hline \multirow[t]{2}{*}{ Female } & Control group & $34(66.7)$ & $51(46.4)$ & $7(38.9)$ & $13(54.2)$ & $>0.05$ \\
\hline & Experimental group & $17(33.3)$ & $59(53.6)$ & $11(61.1)$ & $11(45.8)$ & \\
\hline
\end{tabular}

\subsection{Impact of the Dietary Monitoring App on Nutrition Knowledge}

All mean scores of post-GNKQ-R increased significantly from baseline for both the control group and the experimental group (Table 3). ANCOVA analysis demonstrated that all scores in knowledge about healthy food recommendations, food group classification, choosing healthy foods, and diet-related health problems or diseases from the experimental group increased to a significantly greater extent than those from the control group (all $p<0.001)$.

Table 3. ANCOVA comparisons of nutrition knowledge scores.

\begin{tabular}{|c|c|c|c|c|c|c|}
\hline & Control & & Experiment & & & \\
\hline & Baseline & Post & Baseline & Post & $\begin{array}{c}\text { between Groups } \\
f \text {-Value }\end{array}$ & $p$-Value \\
\hline & Mean (s.d.) & Mean (s.d.) & Mean (s.d.) & Mean (s.d.) & & \\
\hline GNKQ-R ${ }^{\delta}$ Section 1 & $12.4(2.68)$ & $13.7(2.80)$ & $13.1(2.48)$ & $14.4(3.54)$ & 1.125 & $>0.05$ \\
\hline GNKQ-R ${ }^{\delta}$ Section 2 & $23.6(4.51)$ & $25.1(5.21)$ & $24.6(4.07)$ & $27.1(5.2)$ & 8.264 & $<0.05$ \\
\hline GNKQ-R ${ }^{\delta}$ Section 3 & $8.1(2.42)$ & $8.5(2.39)$ & $8.5(2.34)$ & $9.3(2.76)$ & 4.931 & $<0.05$ \\
\hline GNKQ-R ${ }^{\delta}$ Section 4 & $14.3(2.88)$ & $14.6(2.75)$ & $14.0(2.69)$ & $15.1(3.61)$ & 4.050 & $<0.05$ \\
\hline GNKQ-R (Total Score) & $58.4(9.61)$ & $61.9(10.57)$ & $60.1(8.67)$ & $65.9(13.25)$ & 5.948 & $<0.05$ \\
\hline
\end{tabular}

${ }^{+}$ANCOVA analysis on post-GNKQ-R scores as the dependent variable and pre-GNKQ-R scores as the controlled independent variables.

$\delta$ Section 1 = knowledge about healthy food recommendations; Section $2=$ knowledge about food group classification; Section $3=$ knowledge about choosing healthy foods; Section 4 = knowledge about diet-related health problems or diseases.

\subsection{Impact of the Dietary Monitoring App on Dietary Behavior}

All mean values of energy requirement, energy intake, and nutrients of baseline and post- intervention for both the control group and the experimental group are listed in Table 4. Highlights of nutrient intake changes related to the research questions were sugar, sodium, vitamin C, and dietary fiber were summarized here. Significant decreases in sugar consumption were found in the control group and the experimental group $(p<0.001)$, but the decrease in the experimental group was more significant than that in the control group $(p<0.001)$. In addition, the mean difference of sugar intake for the experimental group was significantly more than that for the control group. Insignificant decreases in sodium consumption were identified within groups $(p>0.05)$, and the decreases between the two groups were similar $(p>0.05)$. In addition, the mean difference of sodium intake for the experimental group was more than that for the control group, although the difference was not significant. Significant increases in dietary fiber consumption were found within groups, $(p<0.001)$, and the increase in the experimental group was significantly higher than the increase in the control group $(p<0.001)$. A decrease in vitamin $C$ intake was identified in the control group, while an increase of vitamin $C$ intake was found in the experimental group. Moreover, the increased intake of vitamin $C$ in the experimental group was significantly higher than that in the control group $(p<0.001)$. 
Table 4. Comparisons of nutrient intake.

\begin{tabular}{|c|c|c|c|c|c|c|}
\hline & Control & & Experiment & & & \\
\hline & Baseline & Post & Baseline & Post & between Groups f-Value ${ }^{\dagger}$ & $p$-Value \\
\hline Energy requirement (calories) & $2182(332)$ & $2197(322)$ & $2386(433)$ & $2420(447)$ & 5.414 & $p<0.05$ \\
\hline Energy intake (calories) & $2278(474)$ & 2036 (395) & $2551(827)$ & 2045 (613) & 35.317 & $p<0.001$ \\
\hline Carbohydrate intake (grams) & $231(69)$ & $215(154)$ & $244(86)$ & $205(59)$ & 23.503 & $p>0.001$ \\
\hline Protein intake (grams) & $166(39)$ & $149(46)$ & $158(62)$ & $129(53)$ & 15.274 & $p<0.001$ \\
\hline Total fat intake (grams) & $76.7(32.7)$ & $64.2(22.6)$ & $104.7(49.8)$ & 78.5 (38.3) & 3.255 & $p>0.05$ \\
\hline Saturated fat intake (grams) & $54.7(24.3)$ & $48.6(17.5)$ & $75.3(37.0)$ & $57.3(29.4)$ & 14.397 & $p<0.001$ \\
\hline Trans fatty acid intake (grams) & $2.4(0.97)$ & $2.2(0.88)$ & $2.7(1.32)$ & $1.33(1.08)$ & 112.390 & $p<0.05$ \\
\hline Cholesterol intake (milligrams) & $446(163)$ & $480(207)$ & $514(239)$ & $492(411)$ & 0.577 & $p>0.05$ \\
\hline Sugar intake (grams) & $72.4(48.3)$ & $60.2(34.4)$ & $100.4(55.8)$ & $53.8(36.9)$ & 53.645 & $p<0.001$ \\
\hline Dietary fibre intake (grams) & $10.3(4.67)$ & $11.8(4.78)$ & $14.4(7.26)$ & $21.2(11.56)$ & 48.625 & $p<0.001$ \\
\hline Sodium intake (milligrams) & 3611 (1164) & $3794(3653)$ & $3590(1498)$ & $3659(3989)$ & 0.082 & $p>0.05$ \\
\hline Calcium intake (milligrams) & $299(140)$ & $312(151)$ & $328(189)$ & $594(420)$ & 60.109 & $p<0.001$ \\
\hline Vitamin C intake (milligrams) & $25.8(24.4)$ & $22.9(20.4)$ & $35.4(34.7)$ & $55.4(46.7)$ & 64.442 & $p<0.001$ \\
\hline Vegetable consumption (grams) & $233(106)$ & $267(109)$ & $327(165)$ & $456(223)$ & 49.555 & $p<0.001$ \\
\hline Fruit consumption (grams) & $32.7(36.8)$ & $26.1(28.3)$ & $37.8(42.89)$ & $61.6(70.0)$ & 43.258 & $p<0.001$ \\
\hline
\end{tabular}

${ }^{\dagger}$ ANCOVA analysis on post-energy requirement, post-energy intake, and post-nutrient intake as dependent variables, and pre-energy requirement, pre-energy intake, and pre-nutrient intake as the controlled independent variables, respectively.

\subsection{Impact of the Dietary Monitoring App on Fruit and Vegetable Consumption}

Mean daily intake of fruit and vegetables was recorded at baseline (week 1) and post-intervention (week 12). Mean (s.d.) daily fruit consumption for the control group decreased from 32.7 (36.79) grams to 26.0 (28.31) grams, while that for the experimental group increased from $37.8(42.89)$ grams to $61.6(69.98)$ grams. Significant differences were found within groups $\mathrm{F}_{(1,303)}=40.304, p<0.001$, but the increase in fruit intake was significantly higher in the experimental group than that in the control group $(p<0.001)$. Mean (s.d.) daily vegetable consumption for the control group increased from 233.3 (106.1) grams to 267.0 (109.0) grams, while that for the experimental group increased from 327.2 (165.1) grams to $456.2(222.5)$ grams. Significant differences were identified within groups $\mathrm{F}_{(1,303)}=28.905, p<0.001$, and the increase in vegetable intake was significantly higher in the experimental group than that in the control group $(p<0.001)$ (Table 4$)$.

\subsection{Predictors of Fruit and Vegetable Consumption}

Stepwise regression was computed with the factors of group allocation, post total GNKQ score, gender, age, and BMI categories to explore the significant factors contributing to the variances of fruit and vegetable consumption. The results showed that the intervention group was the most correlated with fruit consumption at step $1, \mathrm{~F}_{(1,303)}=34.088$, $p<0.001$ ) with $r=0.318$. The regression coefficient of step 1 was $\mathrm{B}=35.564$ and $\mathrm{R}$ Squared $=0.101$. At step 2, BMI category exhibited the highest significant partial correlation to fruit consumption, $\left.\mathrm{F}_{(2,302)}=19.488, p<0.001\right)$ with $r=0.338$. The regression coefficient of step 2 was $B=35.905$ and $R$ Squared $=0.114$. No other excluded variables were determined to be significantly correlated with fruit consumption in step 2 , and the stepwise regression ended at step 2.

Stepwise regression revealed that the intervention group was the most correlated with vegetable consumption at step $\left.1, \mathrm{~F}_{(1,303)}=89.446, p<0.001\right)$ with $r=0.477$. The regression coefficient of step 1 was $B=189.188$ and $R$ Squared $=0.228$. No other excluded variables were identified to be significantly correlated with vegetable consumption in step 1 , and the stepwise regression ended at step 1.

\subsection{Feedback on the Application of the Dietary Monitoring App}

Three participating younger adults were invited to take part in an interview to collect their feedback on their experience in using the dietary monitoring app.

(a) User experience in the dietary recording process 
User A recalled that she was not familiar with the dietary monitoring process, but that she became able to monitor her daily diet not long afterwards. User B needed some time to make dietary recording as a habit. She used to forget to input intake of food items, enter the daily diet records, or take photographs of new food items. However, after some practice, User B stated that she became accustomed to keeping her dietary records on a daily basis. Regarding the user interface, User A, User B, and User C found that the app was easy to use. Nevertheless, certain technical problems were found, for example, User A occasionally could not upload food photographs, and she waited for a long time for the screen to be updated. User $C$ remarked that the dietary recording process was smooth, but that if she ate food at a higher number of portions, she needed to scroll down further to get her input correctly. She also felt that the choices of portion size with a half portion apart were not realistic for actual intake. User B also stated that the optional questions in dietary input were confusing. For instance, she was unsure if she should record sauce as consumption of soup, or if it was necessary to input the weight of food if it was not a pre-packaged food.

(b) User reflection on the whole intervention process

User A agreed that the dietary monitoring app helped her to reflect on her daily food intake, which increased her awareness of healthy eating, leading her to gradually establish good eating habits. She appreciated that the online food report and nutrient report allowed her to visualize the calorie intake and nutrient intake of each meal. For foods other than pre-packaged foods, the dietary reports facilitated User A to understand the nutrient content of her food choices. She stated that the dietary monitoring app made her reflect on three important points about healthy eating: first, she should not eat too much in a single meal; second, the intake limits of calories were determined by physical activity level; and third, food intake should be distributed over several meals. User B remarked that she was not previously aware of her nutrient intake, and that during the whole intervention process, she paid more attention to calorie intake, vitamin intake, and calcium intake in each meal. User B agreed that the whole intervention process was useful because she knew that there were nutrient labels in pre-packaged food and the nutrient information was easily found in pre-packaged food. User B stated that he had previously ignored nutrient values of food from different meals in her daily life, but that they contributed to more daily food consumption. Therefore, User B found the entire intervention process beneficial to her understanding of healthy eating. User $\mathrm{C}$ also remarked that the online food report and online nutrient report revealed important, and often obscured, nutritional truth. In other words, even if a food appears to be healthy, their consumption should still not exceed the recommended level, such as in the case of white rice. User C reflected that she understood that the calorie limit could be related to physical activities when she reviewed his online reports during the intervention process. In addition, before she used the dietary recording system, she thought that a high sugar level was limited to those foods that tasted sweet. After the whole intervention process, however, she knew how to avoid high sugar content foods or to choose foods with a lower glycemic index.

(c) User suggestions after the intervention

User A suggested that dietary monitoring apps should be promoted to the elderly population living in the community. NGOs could also assist the elderly to monitor their dietary intake regularly, and health educators could serve as facilitators to explain the online food reports and nutrient reports to the elderly. Overall, she believed that the elderly could especially benefit from dietary monitoring apps.

\section{Discussion}

Although the younger generation has begun to assume responsibility for their dietary habits, most of them have unhealthy eating behaviors with a low intake of fruits, vegetables, and whole grains $[36,37]$. Younger adults are also comfortable with technology and social media. Since their priorities in obtaining knowledge tend towards efficiency and convenience, they found this new concept of healthy eating promotion to be an appropriate way 
to acquire the skills to make good food choices and establish a balanced diet. Indeed, this modality of learning presents no constraints in terms of scheduled time, transportation, and location. It is also expected that this project could probably be effectively applied to other age groups to assimilate acquired nutrition knowledge with an eating plan. The process of behavioral feedback also encourages users to identify and solve problems on their own [25]. Through repeated reflective learning via behavioral feedback, other users in the community may find it easy to connect eating problems with food choices, and to implement practical dietary advice that follows recommended guidelines of healthy eating.

Prior studies suggested that nutrition knowledge is associated with higher intake of vegetables [36], and thus public health initiatives that focus on nutritional knowledge could be one sustainable option to increase healthy eating [37-39]. The current study indicated that the younger adults attending the nutrition seminar only, and those attending the nutrition seminar and using the dietary monitoring app, both improved their nutrition knowledge. However, having the dietary monitoring app for the purpose of dietary reflection made the younger adults more capable of matching food products to food categories, choosing healthy foods, and selecting foods to reduce health problems or risk of diseases. Healthy eating knowledge promoted to younger adults should also be unique to address their specific food access and dietary inquiries. Indeed, their individual problems in dietary patterns should be channeled to them as feedback to take effective actions. Their eating problems should be easily traced in their dietary records and dietary analyses, and immediate corresponding modifications should be made in their meal plans. To facilitate such interactive learning, dietary monitoring apps with reflective feedback are able to provide effective awareness in younger adults for changing their lifestyle in terms of healthy eating. It is found that younger adults' self-reflection is feasible with eDietary Portal. The eDietary Portal empower younger adults to take control of identifying their individual eating problems and correcting their eating problems through proper food choices.

Regarding salt consumption, which was indicated by the outcome measure of sodium intake, the findings did not demonstrate a significant decrease from using the dietary monitoring app. However, the results indicated that the experimental group reduced its sugar consumption more than the control group. Participants may find it easy to avoid simple sugar, which is easily identified by a sweet taste. For example, they could eat less sweet-tasting foods and choose beverages without a sweet taste. Salt content in food, however, could be more difficult to avoid. Foods prepared at home could be controlled by adding less salt, or soy sauce or oyster sauce instead. It is also worth noting that salt is invisible. Indeed, foods served in restaurants could not be assessed for sodium content by the name of dishes, ingredients, or photographs of foods. This is an especially concerning issue because younger adults tend to dine-out comparatively more frequently in their daily life. This may be the primary reason that participants found it easy to increase their fruit and vegetable consumption and avoid sugar intake, but not to choose less salt in their foods.

For whole grain consumption, an increase in dietary fiber was found in both groups, with the experimental group increasing their dietary fiber statistically more than the control group. Moreover, the increase of dietary fiber intake, with a significant decrease in carbohydrate consumption, indicated a shift of food choice from starchy foods to whole grain foods. An improvement in whole grain consumption was supported in both groups, and the participants using the dietary monitoring app improved their whole grain consumption to a significantly greater extent than those in the control group. This demonstrated that participants obtained more awareness in adjusting their foods to whole grain food during the dietary monitoring process. Through the online reports, participants in the experimental group identified food choices with more dietary fiber and could continue to consume relatively more of those foods. This effect is attributed to the behavioral feedback of the reflection process, in which participants identified their eating problems by reviewing the online reports [30]. 
In this study, participants in the experimental group were found to consume more fruits and vegetables than those in the control group. This finding probably suggests that fruits and vegetables are comparatively easy to purchase and order, and thus to consume more of them. A recent review indicated that vegetable consumption is a less researched area when compared with fruit consumption [40]. This is attributable to the fact that research is commonly designed with fruit and vegetable consumption as an integrated outcome measurement; if separately taken into account; however, fruit consumption is usually higher than vegetable consumption [40]. The findings in the current study can provide an effective pathway to promote vegetable consumption in the process of selfdietary monitoring with behavioral feedback.

Abdel-Megeid and colleagues [41] reported that a lower BMI is associated with a higher intake of vegetables. In the present study, BMI categories improved prediction by $1.3 \%$, indicating that higher body sizes further improved fruit consumption with dietary monitoring. However, a similar finding was not present concerning vegetable consumption. This observation was in accordance with Abdel-Megeid et al.'s [41] findings and supported the assertion that vegetable consumption is comparatively more difficult to promote among younger adults. Our results regarding BMI categories may explain that a higher BMI category influences fruit consumption, but a lower BMI category influences vegetable consumption. Further studies are required to confirm these findings.

\section{Limitations}

The present study possesses several limitations. For example, the sampling strategy was performed according to convenience, which may limit the generalizability of the findings. In addition, this project used a mobile app as the means to promote healthy eating. Consequently, participants who were more familiar with mobile technology and more accustomed to using apps may benefit more from the intervention. On the other hand, participants who may have a lower education background, lower technology literacy, less experience in using mobile apps, lower income, and work more hours per week may encounter difficulties in using this intervention for dietary reflection. However, the project team believes that, with the greater coverage of smart phone applications in the population and the well-equipped infrastructure of 4G and 5G technology in the near future, the overall population will become increasingly familiar with mobile apps. Regarding the major benefits of saving transportation time and recording dietary records entirely according to one's own schedule, mobile apps in healthy diet promotion could be effectively generalized to other age groups, such as patients with chronic diseases, as well as elderly and minority groups, which may have relatively less access to dietary knowledge. In addition, health care providers can use these dietary monitoring apps in a highly cost-effective manner. The heathy eating tips implemented in this research contributed greatly to its success in good compliance with the dietary monitoring process. With no systematic encouragement in sending healthy eating tips, the significant results achieved by younger adults during the dietary monitoring process could be discounted. As the implementation of the dietary recording process required health educators to work along with the participants, the applications of eDietary Portal as dietary monitoring may limit scalability to a larger population to be conducted at the same time.

\section{Conclusions}

Dietary monitoring with behavioral feedback promoted younger adults to reduce sugar consumption and increase fruit and vegetable consumption. For those younger adults with increased body size, they were more likely to increase fruit consumption with the application of dietary monitoring. The effectiveness could be predicted to be markedly expanded to other populations due to increasing adoption of technology and expanding technological infrastructure. 
Author Contributions: L.M.Y.C. led the conceptualization and drafting of this manuscript with the review from S.S.M.F. and Q.P.S.L. Funding acquisition was conducted by all authors. Project administration was performed by Q.P.S.L. Methodology and data curation were administered by L.M.Y.C. All authors have read and agreed to the published version of the manuscript.

Funding: This research was supported by the Health Care and Promotion Scheme of the Food and Health Bureau (grant number 01170038).

Institutional Review Board Statement: The study was conducted according to the guidelines of the Declaration of Helsinki, and approved by the Human Research Ethics Committee of The Education University of Hong Kong (project code 01170038 and date of approval: 1st February 2018).

Informed Consent Statement: Informed consent was obtained from all subjects involved in the study.

Data Availability Statement: Data available on request due to restrictions in external funding support.

Acknowledgments: The authors express gratitude to the Kwai Tsing Safe Community and Healthy City Association for their collaboration in participant recruitment, seminar room arrangement, and logistical support.

Conflicts of Interest: The authors declare no conflict of interest.

\section{References}

1. Allman-Farinelli, M.; Chey, T.; Bauman, A.E.; Gill, T.; James, W.P.T. Age, period and birth cohort effects on prevalence of overweight and obesity in Australian adults from 1990 to 2000. Eur. J. Clin. Nutr. 2008, 62, 898-907. [CrossRef] [PubMed]

2. Flegal, K.M.; Carroll, M.D.; Kit, B.K.; Ogden, C.L. Prevalence of obesity and trends in the distribution of body mass index among US adults, 1999-2010. JAMA 2012, 307, 491-497. [CrossRef] [PubMed]

3. Lewis, C.E.; Jacobs, D.R., Jr.; McCreath, H.; Kiefe, C.I.; Schreiner, P.J.; Smith, D.E.; Williams, O.D. Weight gain continues in the 1990s: 10-year treands in weight and overweight from the CARDIA study. Coronary Artery Risk Development in Young Adults. Am. J. Epidemiol. 2000, 151, 1172-1181. [CrossRef] [PubMed]

4. Australian Bureau of Statistics. Australian health Survey: First Results, 2014-2015; Commonwealth Government of Australia: Canberra, ACT, Australia, 2015.

5. Surveillance and Epidemiology Branch, Department of Health. Report of Population Health Survey 2014/2015. Hong Kong SAR. 2017. Available online: http:/ / www.chp.gov.hk. (accessed on 2 December 2020).

6. Briggs, A.D.; Mytton, O.T.; Kehlbacher, A.; Tiffin, R.; Rayner, M.; Scarborough, P. Overall and income specific effect on prevalence of overweight an obesity of $20 \%$ sugar sweetened drink tax in UK: Econometric and comparative risk assessment modelling study. BMJ Open 2013, 347, f6189. [CrossRef]

7. Kit, B.; Fakhouri, T.H.; Park, S.; Nielsen, S.J.; Ogden, C.L. Trends in sugar sweetened beverage consumption among youth and adults in the United States: 1999-2010. Am. J. Clin. Nutr. 2013, 98, 180-188. [CrossRef]

8. Larson, N.; Neumark-Sztainer, D.; Laska, M.N.; Story, M. Young adults and eating away from hone: Associations with dietary intake patterns and weight status differ by choice of restaurant. J. Am. Diet. Assoc. 2011, 111, 1696-1703. [CrossRef]

9. Australian Bureau of Statistics. Australian Health Survey: Nutrition First Results-Food an Nutrients; Commonwealth Government of Australia: Canberra, Australia, 2014.

10. Lloyd-Jones, D.M.; Liu, K.; Colangelo, L.A.; Yan, L.L.; Klein, L.; Loria, C.M.; Lewis, C.E.; Savage, P. Consistently stable or decreased body mass index in young adulthood and longitudinal changes in metabolic syndrome components: The Coronary Artery Risk Development in Young Adults Study. Circulation 2007, 115, 1004-1011. [CrossRef]

11. Ko, G.T.C.; Chan, J.C.N.; Tong, S.D.Y.; Chan, A.W.Y.; Wong, P.T.S.; Hui, S.S.C.; Kwok, R.; Chan, C.L.W. Associations between dietary habits and risk factors for cardiovascular diseases in a Hong Kong Chinese working population-the "Better Health for Better Hong Kong" (BHBHK) health promotion campaign. Asia Pac. J. Clin. Nutr. 2007, 16, 757-765.

12. Lowering Blood Cholesterol to Prevent Heart Disease. NIH Consensus Development Conference Statement. Nutr Rev. 1985, 43, $283-291$.

13. Food and Health Bureau. Boards and Committees. Committee on Reduction of Salt and Sugar in Food. Hong Kong: 18 July 2019. Available online: https:/ /www.fhb.gov.hk/en/committees/crss.html. (accessed on 2 December 2020).

14. Centre for Food Safety. Hong Kong Pollution-Based Food Consumption Survey 2005-2007; Final Report: HKSAR; Centre for Food Safety: Hong Kong, 2010.

15. Worsley, A. Nutrition knowledge and food consumption: Can nutrition knowledge change food behaviour? Asia Pac. J. Clin. Nutr. 2002, 11, 579-585. [CrossRef]

16. Anderson, P.M.; Butcher, K.F.; Levine, P.B. Maternal employment and overweight children. J. Health Econ. 2003, 22, 477-504. [CrossRef]

17. Poobalan, A.S.; Aucott, L.S.; Clarke, A.; Smith, W.C.S. Diet behavior among young people in transition to adulthood (18-25 year olds): A mixed method study. Health Psychol. Behav. Med. 2014, 2, 909-928. [CrossRef] [PubMed]

18. Munt, A.E.; Partridge, S.R.; Allman-Farinelli, M. The barriers and enablers of healthy eating among young adults: A missing piece of the obesity puzzle: A scoping review. Obes. Rev. 2017, 18, 1-17. [CrossRef] [PubMed] 
19. Anderson, E.S.; Winett, R.A.; Wojcik, J.R. Self-regulation, self-efficacy, outcome expectations, and social support: Social cognitive theory and nutrition behavior. Am. Behav. Med. 2007, 34, 304-312. [CrossRef] [PubMed]

20. Pagoto, S.; Schneider, K.; Jojie, M.; DeBiasse, M.; Mann, D. Evidence-based strategies in weight-loss mobile apps. Am. J. Prev. Med. 2013, 45, 576-582. [CrossRef] [PubMed]

21. Laing, B.Y.; Mangione, C.M.; Tseng, C.H.; Leng, M.; Vaisberg, E.; Mahida, M.; Bholat, M.; Glazier, E.; Morisky, D.E.; Bell, D.S Effectiveness of a smartphone application for weight loss compared with usual care in overweight primary care patients: A randomized, controlled trial. Ann. Intern. Med. 2014, 161, S5-S12. [CrossRef]

22. Duncan, M.J.; Vandelanotte, C.; Rosenkrantz, R.R.; Caperchione, C.M.; Caperchione, C.; Ding, H.; Ellison, M.; George, E.S.; Hooker, C.; Karunanithi, M.; et al. Effectiveness of a website and mobile phone based physical activity and nutrition intervention for middle-aged males: Trial protocol and baseline findings of the ManUp Study. BMC Pub. Health 2012, 12, 656. [CrossRef]

23. Six, B.L.; Schap, T.E.; Zhu, F.M.; Mariappan, A.; Bosch, M.; Delp, E.J.; Ebert, D.S.; Kerr, D.A.D.; Boushey, C.J. Evidence-based development of a mobile telephone food record. J. Am. Diet. Assoc. 2010, 110, 74-79. [CrossRef]

24. Ikorok, M.M.; Eka, R.J.; Ogunjimi, L.O.; Udoh, N.B. Determinants of nutritional behaviour of secondary school students in Akwa Ibom State, Nigeria. Int. J. Nutr. Metab. 2012, 4, 94-99.

25. Chung, L.M.Y.; Fong, S.S.M. Role of Behavioural Feedback in Nutrition Education for Enhancing Nutrition Knowledge and Improving Nutritional Behaviour among Adolescents. Asia Pac. J. Clin. Nutr. 2018, 27, 466-472.

26. Svetkey, L.P.; Batch, B.C.; Lin, P.H.; Intille, S.S.; Corsino, L.; Tyson, C.C.; Bosworth, H.B.; Grambow, S.C.; Voils, C.; Loria, C.; et al. Cell phone intervention for you (CITY): A randomized, controlled trial of behavioral weight loss intervention for young adults using mobile technology. Obesity 2015, 23, 2133-2141. [CrossRef] [PubMed]

27. Chung, L.M.Y.; Law, Q.P.S.; Fong, S.S.M.; Chung, J.W.Y.; Yuen, P.P.M. A cost-effectiveness analysis of teledietetics in short-, intermediate-, and long-term weight reduction. J. Telehealth Telecare 2015, 21, 268-275. [CrossRef] [PubMed]

28. Chung, L.M.Y.; Law, Q.P.S.; Fong, S.S.M.; Chung, J.W.Y. Tele-dietetics improves weight reduction by modifying eating behavior: A randomized controlled trial. Telemed. E Health 2014, 20, 55-62. [CrossRef] [PubMed]

29. Chung, L.M.Y.; Law, Q.P.S.; Fong, S.S.M.; Chung, J.W.Y. Electronic dietary recording system improves nutrition knowledge, eating attitude and habitual physical activity: A randomized controlled trial. Eat Behav. 2014, 15, 410-413. [CrossRef] [PubMed]

30. Chung, L.M.Y.; Fong, S.S.M.; Law, Q.P.S.; Ma, A.W.W.; Chow, L.P.Y.; Chung, J.W.Y. Theoretical examination of behavioural feedback in the application of teledietetics on weight reduction. J. Telehealth Telecare 2016, 22, 244-251. [CrossRef]

31. Kliemann, N.; Wardle, J.; Johnson, F.; Croker, H. Reliability and validity of a revised version of the general nutrition knowledge questionnaire. Eur. J. Clin. Nutr. 2016, 70, 1174-1180. [CrossRef]

32. Parmenter, K.; Wardle, J. Development of a General Nutrition Knowledge Questionnaire for adults. Eur. J. Clin. Nutr. 1999, 53, 298. [CrossRef]

33. Peltzer, K. Nutrition knowledge among a sample of urban black and white South Africans. S. Afr. J. Clin. Nutr. 2004, 17, 24-31. [CrossRef]

34. Assya Systems LLC. Nutritionist Pro TM diet Analysis Software. 2009. Available online: http://www.nutritionistpro.com/ dietanalysis.php (accessed on 2 December 2020).

35. Shetty, P.S.; Henry, C.J.; Black, A.E.; Prentice, A.M. Energy requirements of adults: An update on basal metabolic rates (BMRs) and physical activity levels (PALs). Eur. J. Clin. Nutr. 1996, 50, 11.

36. SanchezSocarras, V.; Aguilar Martinez, A. Food habits and health-related behaviours in a university population. Nutr. Hosp. 2014, 31, 449-457.

37. Bernardo, G.L.; Jomori, M.M.; Fernandes, A.C.; Proenca, R.P.D.C. Food intake of university students. Rev. Nutr. 2017, 30, 847-865.

38. Kresic, G.; Kendel Jovanovic, G.; Pavicic Zezel, S.; Cvijanovic, O.; Ivezic, G. The effect of nutrition knowledge on dietary intake among Croatian university students. Coll. Antropol. 2009, 33, 1047-1056.

39. Teschl, C.; Nössler, C.; Schneider, M.; Carlsohn, A.; Lührmann, P. Vegetable consumption among university students: Relationship between vegetable intake, knowledge of recommended vegetable servings and self-assessed achievement of vegetable intake recommendations. Health Educ. J. 2018, 77, 398-411.

40. Rodrigues, V.M.; Bray, J.; Fernandes, A.C.; Bernardo, G.L.; Hartwell, H.; Martinelli, S.S.; Uggioni, P.L.; Cavalli, S.B.; Proenca, R.P.D.C. Vegetable consumption and factors associated with increased intake among college students: A scoping review of the last 10 years. Nutrients 2019, 11, 1634. [CrossRef] [PubMed]

41. Abdel-Megeid, F.Y.; Abdelkarem, H.M.; El-Fetouh, A.M. Unhealthy nutritional habits in university students are a risk factor for cardiovascular diseases. Saudi Med. J. 2011, 32, 621-627. [PubMed] 